\title{
Identification of the Pathogenic Bacteria Contaminated Canine Feeding Process
}

\author{
Ahmed Fawaz Salim*, E. S. Siham and M. A. Abdalla \\ College of Veterinary Medicine, Sudan University of Science and Technology, \\ Khartoum North, Sudan \\ *Corresponding author
}

\begin{abstract}
A B S T R A C T
This study was conducted in Al-Ain (Abu Dhabi Emirate) at the Police Dogs Unit K9, to detect the load of bacterial contamination at the critical control points of canine feeding process and these are kennel floor, handlers' hands, the bowls before and after meal and meat canned food. A number of 300 swabs samples were taken from the five points on duration of ten consecutive weeks. The samples were sent to the Central veterinary laboratory for microbiological analysis. The results displayed a variety of contaminants were identified at the stages of the feeding processes, a highest bacterial viable counts were at the kennel floor $\left(4.21 \log _{10} \mathrm{cfu} / \mathrm{cm}^{2}\right)$ and the Bowls after meal $\left(5.05 \log _{10} \mathrm{cfu} / \mathrm{cm}^{2}\right)$, while the low or nearly neglected bacterial count was in the canned food $(0.78$ $\left.\log _{10} \mathrm{cfu} / \mathrm{cm}^{2}\right)$. Accordingly, Staphylococcus aureus and Escherichia coli were seen at lower mean bacterial count at points of handlers' hands $(0.34 \%, 0.06 \%)$ and canned food $(0.00 \%, 0.06 \%)$, while they were highest at the kennel floor $(25.54 \%, 60.05 \%)$ and the Bowls after meal $(70.89 \%, 36.46 \%)$, respectively. This study has shown that the highest bacterial contamination in Police dogs' feeding processes is at the bowls after meal and kennel floor and the lowest at the handler's hands and the canned food, and also that Staphylococcus aureus and Escherichia coli were the major pathogenic contaminants in the feeding processes.
\end{abstract}

\section{Keywords}

Canine Feeding Process, HACCP

Article Info

Accepted:

12 November 2020

Available Online:

10 December 2020

\section{Introduction}

The Hazard Analysis and Critical Control Points (HACCP) system has become a synonymous with food safety. It is a worldwide-recognized systematic and preventive approach that addresses biological, physical and chemical hazards through anticipation and prevention rather than through end-product inspection and testing (FAO, 1998).
The best food is one that meets all the nutritional requirements necessary for gog health. Dry food which is the most economical type of commercial food. But canned food or wet food has shelf live and preferred by dogs. The least nutritional value of all dogs feed is semi-moist food (Pork, burgers or other meaty food). While home cooked food used by owners is time consuming and expensive. Whereas, raw food (mixture of bones and organs) is good for 
many dogs (Nylabone, 2019).Macrobiotic of canine digestive tract plays a major role in defensive mechanism (Gison and Wang, 1994). The growth of foreign microorganisms entering the tract with food and water is inhibited by the action of the antimicrobial substances of the intestinal flora and dogs are quite resistant to Salmonella spp. and require a large dose to cause infection (Carnivora, 2019). The aims of canning process to prevent food from spoilage and preserve the quality of the food and kept it for an extended period of time without refrigeration and without loss of nutrition values (Blumental, 1990). But microorganisms that contaminated processed pet food are responsible for digestive tract diseases such as diarrhea, vomiting, nausea and abdominal pain. Improper storage of opened canned food is another factor contributing to spoilage of canned food. Also, environmental temperature and oxygen availability influence the bacterial growth in opened canned food (FDA, 2001). There are many types of oral bacteria in dogs also can cause severe diseases and death (Kaisompimolpore et al., 2003; Dewhirst et al., 2012).

Training and education of food handlers are best ways for food safety that by knowing safe cooking temperature, proper storage of high - risk food, sanitation measures, sound management and personal hygiene (AIFS, 2016). The aim of this study was to assess and identify the pathogenic bacteria and their load in the critical control points of canine feeding process.

\section{Materials and Methods}

\section{Area study}

The study was conducted at Police Dog Unit, Al Ain city, Abu Dhabi, United Arab Emirates. The swabs were collected from Dogs' Kennels during period of ten weeks.

\section{Collection of samples}

A total of 300 swab samples were collected from dogs' kennels, 30 swabs was taken weekly from the kennel, precisely from five critical points CCPs: kennel floor, bowls before meal, bowls after meal, handlers' hands, and canned food.

The kennels floor was made up of concrete tiles. Feeding bowls were round shape and made of stainless steel. The canned food was purchased from known company.

The 30 samples were repeated and taken from the same five stages CCPs from the kennel for 10 consecutive weeks.

The swab samples were collected in sterile tubes and preserved in cooled container and transferred to laboratory for Microbiological analysis.

The targeted bacteria in this study were: Staphylococcus aureus, Salmonellae, Escherichia coli, and Clostridium perfringens.

\section{Collection of swab samples for microbiological testing}

Selecting sampling area of about $10 \mathrm{~cm} \mathrm{X} 10$ $\mathrm{cm}$ (or $20 \mathrm{~cm}$ x $20 \mathrm{~cm}$ ). The swab was rubbed and rolled firmly several times across the sampling area, then the samples were labeled and preserved until used.

\section{Total Viable Count (TVC)}

The total viable count of isolated microorganisms was carried out using serial dilution to each sample (Harrigan and McCance, 2014).

The samples were transferred to a nutrient broth test tube, then $5 \mathrm{ml}$ of the solution is 
incubated at $37^{0} \mathrm{C}$ for $18-24$ hours (overnight) for bacterial growth. Firstly, serial dilutions prepared from the Normal Saline solution included bacteria to be diluted, then serial folds' dilution in sterile test tubes each contains $9 \mathrm{ml}$ Normal Saline was be prepared. One $\mathrm{ml}$ of nutrient broth with drawn by micro pipette and added to the first tube of $9 \mathrm{ml}$ normal saline dilute 1 .

From the first dilution 1/10 take $1 \mathrm{ml}$ and add to the second tube of $9 \mathrm{ml}$ normal saline the dilution was 1/100and the process was repeated until reach $1 / 100000$ concentration. From the $4^{\text {th }}$ tube $(1 / 10000)$ using micropipette take $1 \mathrm{ml}$ and spread it over the surface of Petri dish which contains Nutrient Agar (count plate). The plate incubated overnight at $37^{\circ} \mathrm{c}$ for 24 hours. The colonies were counted after formation (Miles and Misra (1938)

\section{Statistical analysis}

Data were analyzed using SPSS software (Statistical Package for the Social Sciences, version 16.0, SSPS Inc. And Chicago, IL, USA). All bacterial counts were converted to $\log { }_{10} \mathrm{CFU} / \mathrm{CM}^{2}$. All bacterial counts were analyzed, and descriptive statistical method and ANOVA were performed. Statistical significance was set at a P-value of $\leq 0.05$ (Table 1).

\section{Results and Discussion}

Contamination at the points of bowls after meal was $37.60 \%$ with mean count of $5.05 \mathrm{cfu} / \mathrm{cm}^{2}$, and kennel floor was $31.31 \%$, with mean count of $4.21 \mathrm{cfu} / \mathrm{cm}^{2}$, and low counts were detected in the canned food with $5.88 \%$ and mean value of $0.78 \mathrm{cfu} / \mathrm{cm}^{2}$, and handlers hands $(6.26 \%)$ mean count of $0.89 \mathrm{cfu} / \mathrm{cm}^{2}$.

\section{Isolation and identification of bacteria}

Only two types of bacteria were isolated and identified at the five stages of feeding process and these were Staphylococcus aureus, and Escherichia coli.

Table 2 illustrates the concentration (\%) of $E$. coli at the different stages of feeding process. High load of contamination by $E$. coli was detected at kennel floor $(60.05 \%)$ and at the bowls after meal $(34.46 \%)$. Neglected load was seen at the points of canned food and handlers' hands.

The obtained results indicated that $S$. aureus was the most contaminant bacteria than $E$. coli at the different stages. E. coli was mostly seen in high load at the kennel floor rather than other stages (Table 3 and 4). The study shows a statistically significance difference at $(\mathrm{P} \leq 0.05)$ for the critical points.

Table.1 Mean and standard Deviation, Standard Error and Percentage of Total 1: Viable Counts of Bacterial Contamination $\left(\left(\log ^{10} \mathrm{cfu} / \mathrm{cm}^{2}\right)\right.$ at Different Stages of dogs (300) Feeding Process in Al-Ain_City

\begin{tabular}{|l|cc|c|c|c|}
\hline CCPs & \multicolumn{2}{|c|}{$\begin{array}{c}\text { Mean }\left(\mathbf{l o g}^{\mathbf{1 0}} \mathbf{c f u} / \mathbf{c m}^{\mathbf{2}}\right) \\
\mathbf{S T T D . D E V}\end{array}$} & $\begin{array}{c}\text { Standard } \\
\text { Error }\end{array}$ & $\begin{array}{c}\text { Significant } \\
\text { Difference }\end{array}$ & Percentage \\
\hline Kennel Floor & 4.21 & \pm 0.75 & 0.09 & $* *$ & $31.36 \%$ \\
\hline Bowls Before Meal & 2.55 & \pm 0.27 & 0.35 & $* *$ & $18.90 \%$ \\
\hline Bowls After Meal & 5.05 & \pm 0.46 & 0.05 & $* *$ & $37.60 \%$ \\
\hline Handlers Hands & 0.89 & \pm 0.05 & 0.00 & $* *$ & $6.26 \%$ \\
\hline Opened canned Food & 0.78 & \pm 0.10 & 0.13 & $* *$ & $5.88 \%$ \\
\hline
\end{tabular}


Table.2 Evaluation of E. coli $(\%)$ at Different Stages of dogs $(n=250)$ feeding process in Al-Ain_City

\begin{tabular}{|l|l|}
\hline CCPs & Percentage \% \\
\hline Kennel Floor & $60.05 \%$ \\
\hline Bowls before meal & $3.37 \%$ \\
\hline Opened canned Food & $0.06 \%$ \\
\hline Handlers hand & $0.06 \%$ \\
\hline Bowls after meal & $36.46 \%$ \\
\hline Total & $100 \%$ \\
\hline
\end{tabular}

Table.3 Evaluation of Staphylococcus aureus (\%) at Different Stages of dogs $(n=300)$ feeding process in Al-Ain_City

\begin{tabular}{|l|l|}
\hline CCPs & Percentage \% \\
\hline Kennel Floor & $25.54 \%$ \\
\hline Bowls before meal & $3.23 \%$ \\
\hline Opened canned Food & $0.00 \%$ \\
\hline Handlers hand & $0.34 \%$ \\
\hline Bowls after meal & $70.89 \%$ \\
\hline Total & $100 \%$ \\
\hline
\end{tabular}

Table.4 Percentage of Staphylococcus aureus and Escherichia coli isolated and identified at the different stages of $\operatorname{dog}(n=300)$ feeding process in Al-Ain_City

\begin{tabular}{|l|c|c|c|}
\hline CCP & S. aureus & E. coli & Total \\
\hline Kennel Floor & $24.87 \%$ & $1.58 \%$ & $26.45 \%$ \\
\hline Bowls before meal & $3.15 \%$ & $0.09 \%$ & $3.24 \%$ \\
\hline Bowls after meal & $69.03 \%$ & $0.96 \%$ & $69.98 \%$ \\
\hline Handlers hands & $0.33 \%$ & $0.00 \%$ & $0.33 \%$ \\
\hline Opened canned food & $0.00 \%$ & $0.00 \%$ & $0.00 \%$ \\
\hline TOTAL & $97.38 \%$ & 2.63 & $100.00 \%$ \\
\hline
\end{tabular}

In this study, a variety of contaminants were identified at the stages of the feeding processes, which displayed a highest bacterial viable count (TVC) at the kennel floor, and the bowls after meal. These contaminants are supposed to be shed from the feces of dogs, their oral saliva, or nasal discharge, or from the dog handlers (Rita et al., 2007). Staphylococcus aureus and Escherichia coli were seen at lower mean bacterial count (TVC) at points of handlers' hands and canned food. The low or nearly neglected bacterial counts in the canned food is in accordance to the ICMSF (International Commission on Microbiological Specifications for Foods), Canned pet foods are terminally heat processed in hermetically sealed containers and are commercially sterile. They are subject to the regulations for low-acid canned foods, and when in compliance are not of public health concern (Silliker and ICMSF, 1980). Intermediate wet pet foods and the dry kibbles are subjected to a heat process during extrusion and pelleting 
that will destroy the vegetative cells of pathogenic bacteria. The prevention of recontamination following heating, then, it is the critical control step in their processing (İnal et al., 2018).

Matching of the results of pathogenic microorganisms in ready-to-eat food (RTE) with the standards of Compendium of Microbiological Criteria for Food (FSANZ, 2018), interpreting results of $\mathrm{cfu} / \mathrm{g}$ for $S$. aureus is regarded as satisfactory if it is $<10^{2}$. Results of $<3$ for E. coli is satisfactory and of marginal hazard at the counts of $3-<10^{2}$. It is of health concern to know that Shiga toxin producing E. coli (STEC) is potentially hazardous when detected in $25 \mathrm{~g}$ of (RTE) food. This corresponds to this study as the canned food used for feeding is purchased from known sources using "wholesome" pet foods. The handler's hands also showed a low level of bacterial count which clearly indicates that the standards of hygiene within the K9 facilities under investigation are satisfactory. Staphylococcus aureus is a part of the normal microbiota in humans and animals. It is an opportunistic pathogen noted in clinically healthy individuals.

Food handlers are main source of food contaminating microbes via direct contact as S. aureus is usually present in people nasal passages, throat, and skin. Escherichia coli is a bacterium that is commonly found in the lower intestine of warm-blooded organisms. Most E. coli strains are harmless, but some can cause serious food poisoning. Usually present when self-hygiene is not ensured. These finding in agreement with study by Olsen et al., (2000) who reported that food service establishments are source of foodborne illness and food handlers contribute to food -borne illness outbreaks. Furthermore, according to World Health Organization (WHO, 2009) food handling personnel play a vital role in food safety through the chain of production to storage. One of the major threats of the food industry is that the contamination with food-borne microbes of human origin resulting from improper handling and processing. Handlers may be incriminated in food-borne illness when cross contamination occur during food handling and poor hygienic measures.

The data obtained from the kennel floor show a noticeable count of both $S$. aureus and $E$. coli, so oral contamination of infectious agents occur through eating or drinking contaminated food, water, and oral contact with contaminated environmental surfaces such as ground of floor. Staphylococcus aureus is identified at this stage as it is commonly found on the skin of mammals, birds, fomites, and secretions from nasal passages and throat; this is in agreement with Al-Bahry et al., (2014). The presence of $E$. coli in the kennel floor is attributed to the contamination by the feces as the bacteria are found in the large intestine of normal animals. This data is in accordance to the findings of study done by Stella et al., (2018) on how flooring substrate impact kennel and dog cleanliness in breeding facilities of $118 \mathrm{dogs}$ housed on three different types of flooring. They found Thirty-one percent or fewer kennels have fecal contamination and culturepositive for $E$. coli after routine cleaning.

The kennel flooring surfaces were swabbed and cultured for presence of E. coli. The Positive results ranged from $7 \%$ to a higher of $31 \%$ with an average of $23.7 \%$ of samples taken from kennels after cleaning. These findings indicate that a well-managed kennel can maintain healthy dogs on different types of flooring substrate, but concrete flooring types can permit maintenance of dog cleanliness. Such flooring substrate is used in the Police dogs' facilities in this study, though, standard cleaning protocols should be implemented to minimize Coliform recovery 
to promote dog physical health and hygiene and prevent cross-contamination.

The mean TVC obtained from the feeding bowls before and after meal revealed the identification of $S$. aureus and $E$. coli as such, with a considerable count in the bowls after meal, in accordance with the study and results done by Wright and Carrol (2018), who found harmful pathogens, like E. coli and MRSA in plastic and ceramic bowls and less counts in stain-less bowls. In another study by AbdelMoein et al., (2011) who found MethicillinResistant Staphylococcus aureus (MRSA) as an Emerging Pathogen of Pets in Egypt with a Public Health Burden diseases, who looked for enterotoxigenic organism in 70 dogs and 48 pet cats. Swabs were collected from the mouth, nose and wounds. Nasal swabs from 26 people. They isolated enterotoxemic $S$. aureus from $10 \%$ of dogs and $2.1 \%$ of cats, most of the positive results are from pets' oral samples, indicating that dogs can pose a risk and potential source of $S$. aureus that can be incriminated in food poisoning, since it can be presumably shed in saliva. Thus, the increased count in the bowls after meal may be attributed to shedding of saliva, as the oral dog flora contains different types of microorganisms including $E$. coli and $S$. aureus. Another possible way of contamination is of $S$. aureus can be y the skin and hair of dogs, and soiling of the bowls by dogs' own feces might be a source of $E$. coli contamination. Although, bowls are fomites that can bacteria attach to it, and transfer it to anything in touch, that way can spread the bacteria from dog to human and human to dog. This study was faced by some challenges which can be summarized as, scarce of similar studies done, for debating the issues and comparing the results. The study was done in nearly ideal environment, where strict hygienic measures are implemented in the Police K9 unit facilities. In conclusion, the results clearly show that there is contamination at all stages of feeding process in the Kennel under study with variable counts. Staphylococcus aureus and Escherichia coli were isolated and identified at all stages. The highest contamination was seen at the bowls after meal and lowest at the handler's hands and the canned food. The standards of hygiene implemented in the facilities are relatively satisfactory.

\section{References}

Abdel-moein, K., El-Hariri, M. and Samir, A. (2011).

Methicillin-Resistant Staphylococcus aureus: An Emerging Pathogen of Pets in Egypt with a Public Health Burden. Transboundary and Emerging Diseases, 59(4), pp.331-335.

AIFS (2016). Food Safety and the Different Types of Food Contamination. [online] Foodsafety.com.au. Available at: https://www.foodsafety.com.au/resources/ar ticles/food-safety-and-the-different-typesof-food-contamination [Accessed 12 Aug. 2018].

Al-Bahry, S., Mahmoud, I., Al-Musharafi, S. and Sivakumar, N. (2014). Staphylococcus aureus Contamination during Food Preparation, Processing and Handling. International Journal of Chemical Engineering and Applications, 5(5), pp.388-392.

Blumenthal, D. (1990). The Canning Process; Old Preservation Technique Goes Modern. [online] Questia.com. Available at: https://www.questia.com/magazine/1G19009146/the-canning-process-oldpreservation-technique-goes [Accessed 12 Dec. 2019].

Carnivora (2019). Safe handling of raw dog and cat food diets. [online] Carnivora.ca. Available at: https://www.carnivora.ca/html/LearningCentre/The-Question-of-Bacteria/index.cfm [Accessed 19 Dec. 2019].

Dewhirst, F., Klein, E., Thompson, E., Blanton, J., Chen, T., Milella, L., Buckley, C., Davis, I., Bennett, M. and Marshall-Jones, Z. (2012). The Canine Oral Microbiome. PLoS ONE, 7(4), p.e36067. 
FAO (1998). Food Quality and Safety Systems - A Training Manual on Food Hygiene and the Hazard Analysis and Critical Control Point (HACCP) System. [online] Fao.org. Available at: http://www.fao.org/3/w8088e/w8088e00.ht m\#Contents [Accessed 18 Jun. 2018].

FDA (2001). The Food Code is a model for safeguarding public health and ensuring food is unadulterated and honestly presented when offered to the consumer. Available at: https://www.fda.gov/animalveterinary/animal-health-literacy/get-factsraw-pet-food-diets-can-be-dangerous-youand-your-pet [Accessed 18 Jul. 2018].

FSANZ (2018). Compendium of Microbiological Criteria for Food. [online] Foodstandards.gov.au. Available at: https://www.foodstandards.gov.au/publicati ons/Documents/Compedium\%20of\%20Mic robiological\%20Criteria/Compendium_revi sed-Sep\%202018.pdf [Accessed 14 Dec. 2019].

Gibson, G. and Wang, X. (1994). Regulatory effects of bifidobacteria on the growth of other colonic bacteria. Journal of Applied Bacteriology, 77(4), pp.412-420.

Harrigan, W. and McCance, M. (2014). Laboratory Methods in Microbiology. Saint Louis: Elsevier Science.

İnal F, Alataş MS, Kahraman O, İnal Ş, Uludağ M, Gürbüz E, Polat ES (2018).Using of pelleted and extruded foods in dog feeding. Kafkas Univ Vet FakDerg, 24 (1): 131-136, 2018. DOI: $10.9775 / \mathrm{kvfd} .2017 .18529$

Kasempimolporn, S., Benjavongkulchai, M., Saengseesom, W. and Sitprija, V. (2003). Oral bacterial flora of dogs with and without rabies: a preliminary study in Thailand. $J$ Med Assoc Thai, 86(12), pp.1162-6.
Miles, A.A; S.S Misra (1938). The estimation of bactericidal power of the blood. J. Hyg. 38: 732.

Nylabone (2019). Types of Dog Food | Choosing Dog Food | Nylabone. [online] Nylabone Dog Toys, Chews, Treats, \& Edible Dental Chews. Available at: https://www.nylabone.com/dog101/typesof-dog-food [Accessed 20 Dec. 2019].

Olsen, S. J., MacKinnon, L. C., Goulding, J. S., Bean, N. H., and Slutsker, L. (2000). Surveillance for foodborne disease outbreaks - United States, 1993-1997, Morbidity and Mortality Weekly Report, 49 (1), 1-51. (1993-1997).

Rita Finley, Carl Ribble, and Richard Reid-Smith (2007). The risk of salmonellae shedding by dogs fed Salmonella-contaminated commercial raw food diets. Can.Vet.J. 48(1):69-75.

Silliker, J. and ICMSF (1980). Microbial ecology of foods. New York: Academic Press.

Stella, J., Hurt, M., Bauer, A., Gomes, P., Ruple, A., Beck, A. and Croney, C. (2018). Does Flooring Substrate Impact Kennel and Dog Cleanliness in Commercial Breeding Facilities? Animals, 8(4), p.59.

WHO (2009). Toxicological and Health Aspects of Melamine and Cyanuric Acid. [online] Who.int. Available at: https://www.who.int/foodsafety/publication s/chem/Melamine_report09.pdf [Accessed 10 Aug. 2018].

Wright, C. and Carroll, A. (2018). Microbiological Assessment of Canine Drinking Water and the Impact of Bowl Construction Material. In: 69th Annual Meeting of the European Federation of Animal Science.

\section{How to cite this article:}

Ahmed Fawaz Salim, E. S. Siham and Abdalla, M. A. 2020. Identification of the Pathogenic Bacteria Contaminated Canine Feeding Process. Int.J.Curr.Microbiol.App.Sci. 9(12): 16281634. doi: https://doi.org/10.20546/ijcmas.2020.912.193 